\title{
BEAM CHOPPER FOR THE LOW-ENERGY UNDULATOR TEST LINE
}

Y. Kang, J. Wang, S. Milton, L. Teng, K. Thompson, J. Jones, D. Walters, and J. Jagger Advanced Photon Source, Argonne National Laboratory 9700 South Cass Avenue, Argonne, Illinois 60439 USA \begin{abstract}
${ }^{*}$
Abstract

The low-energy undulator test line (LEUTL) is being built and will be tested with a short beam pulse from an if gun in the Advanced Photon Source (APS) at the Argonne National Laboratory. In the LEUTL a beam chopper is used after the if gun to deflect the unwanted beam to a beam dump. The beam chopper consists of a permanent magnet and an electric deflector that can compensate for the magnetic deflection. A $30-\mathrm{kV}$ pulsed power supply is used for the electric deflector. The chopper subsystem was assembled and tested for beamline installation. The electrical and beam properties of the chopper assembly are presented.
\end{abstract}

\section{INTRODUCTION}

A $2.856-\mathrm{GHz}$ thermionic if gun is used for the electron beam generation in the LEUTL [1]. The if gun is capable of generating $1 \mathrm{~A}$ of beam during approximately $2 \mu$ s at a repetition rate of $10 \mathrm{~Hz}$. Such a beam, accelerated to the energies envisioned for the LEUTL (650 MeV), would easily violate the radiation safety envelope of the APS linac vault. The beam chopper was conceived and designed to provide a fail-safe means of chopping the total quantity of generated beam down to a level which can safely be transported within the linac vault at the peak energies attainable. For control of electron beam bunches in the LEUTL, a beam chopper has been designed.

The beam chopper is placed between the of gun and the alpha magnet injector to the linac and easily deflects the $3 \mathrm{MeV}$ beam. The chopper consists of an electrostatic deflector located within a crossed permanent magnetic field. The electrostatic plates are spaced $10 \mathrm{~mm}$ apart and connected to a high voltage switched power supply through coaxial cables. Both plates are raised to $30 \mathrm{kV}$ by the high voltage power supply. The plates are then switched sequentially to ground through a single switch and delay line. The rise and fall times are less than $50 \mathrm{~ns}$. The electron beam can pass and travel to the linac only during the transient switching time determined by the delay lines. otherwise it is directed to a beam dump.

\section{DESIGN AND CONSTRUCTION}

The magnetic deflector is made of a permanent magnet for full-time deflection while the electrostatic deflector is designed to deflect the beam to the original beam axis. The high voltage for the electrostatic deflection is from the pulsed power supply. Figure 1 shows the chopper assembly between two quadrupole magnets in the beamline. The chopper dipole magnet is outside the electrostatic deffector chamber.
The high voltage operation requires special attention 71997 to insulation for reliability and safety. Also the hig veltage short pulse operation requires good electromagna shielding for noise suppression. For this purpose, but not shown in the figure, an aluminum shroud will also be installed around the chopper assembly. A water-cooled copper beam dump with a vertical slot for beam passage is placed in the downstream 2.75" Conflat flange. The design specifications of the chopper system components are shown in Table 1.

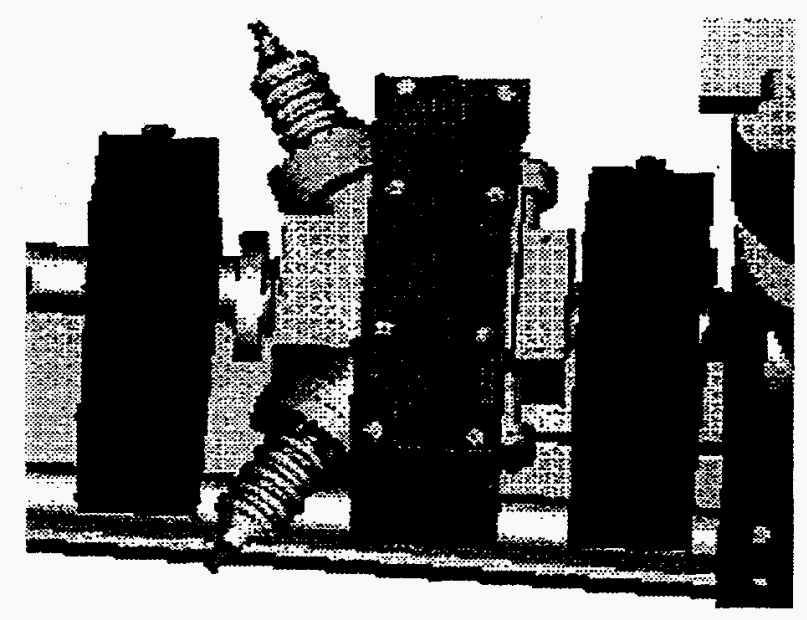

Figure 1: Chopper assembly.

Numerical simulations were made to see the approximate field distribution and if resonance response of the structure. Calculations using the MAFLAcomputer code showed that resonances above $-2.5 \mathrm{GHz}$ are severely damped within the electric kicker chamber. This is due to the loss on the stainless steel wall and the lossy ceramic dielectric of the high voltage feedthroughs and standoffs. The electric field distribution in the chamber was simulated using the Hewlett Packard High Frequency Structure Simulator (HFSS) computer code to see the electric field uniformity. The result showed that the electric field on the beam axis between the parallel electrodes is essentially flat except the fringing fields at both ends.

Table 1: Chopper Specification

\begin{tabular}{cc} 
Beam energy & $3 \mathrm{MeV}$ \\
Deflector plate length & $10 \mathrm{~cm}$ \\
Deflection at exit of plates & $3.57 \mathrm{~mm}$ \\
Deflection angle & $0.071+\mathrm{rad}$ \\
Integrated magnetic field & $82.7 \mathrm{G}-\mathrm{m}$ \\
\hline
\end{tabular}

The submitted manuscript has been created by the University of Chicago as Operator of Argonne National Liboratory " Argonne" i under Contract .io. W-ij-109-ENG-38 with the U.S. Deparment of Energy. The U.S. Government retains for itself, and others acting on its behalf. a paid-up. nonexilusive. irrevocible war!dwide icense in said article to reproduce, prepare derivative works. distribute copies to the public, and pertorm publicly and display publicty. by or on tetalf of the Government 


\section{DISCLAIMER}

This report was prepared as an account of work sponsored by an agency of the United States Government. Neither the United States Government nor any agency thereof, nor any of their employees, make any warranty, express or implied, or assumes any legal liability or responsibility for the accuracy, completeness, or usefulness of any information, apparatus, product, or process disclosed, or represents that its use would not iniringe privately owned rights. Reference herein to any specific commercial product, process, or service by trade name, trademark, manufacturer, or otherwise does not necessarily constitute or imply its endorsement, recommendation, or favoring by the United States Government or any agency thereof. The views and opinions of authors expressed herein do not necessarily state or reflect those of the United States Government or any agency thereof. 


\section{DISCLAMMER}

Portions of this document may be illegible in electronic image products. Images are produced from the best available original document. 


\subsection{Deflector Magnet}

Since the required field strength is low, the dipole magnet has been designed to use a permanent magnet material of ceramic 8 [2]. The magnet structure has a 6.1 $\mathrm{cm}$ verical gap, $10-\mathrm{cm}$-wide iron pole pieces, and 7.94- $\mathrm{cm}$ core lerigth. Figure 2 shows the magnetic flux plot from OPERA-2d [3] for one quarter of the magnet in the transverse plane with respect to the beam axis. At most, a pair of 5-mm-thick slices of permanent magnet material are required between the pole tip and yoke at each pole. The magnet material is strontium oxide-ferrite ceramic from Hitachi. The effective length of the magnet is $10 \mathrm{~cm}$ and compensates the electrostatic deflector. However, the field along the beam axis is not uniform since the length is so short compared to the magnet gap. A pair of permanent magnet blocks is placed between the yoke and each pole piece. Each block measures $1 \mathrm{~cm} \times 0.5 \mathrm{~cm} \times 7.94 \mathrm{~cm}$. The field along the beam axis is shown in Figure 3. The peak field is about $91 \mathrm{G}$. For accuracy of the field, the ceramic magnet is magnetized after machining and the field strength is optimized by placing magnetic steel shims into the air gaps adjacent to the permanent magnet blocks.

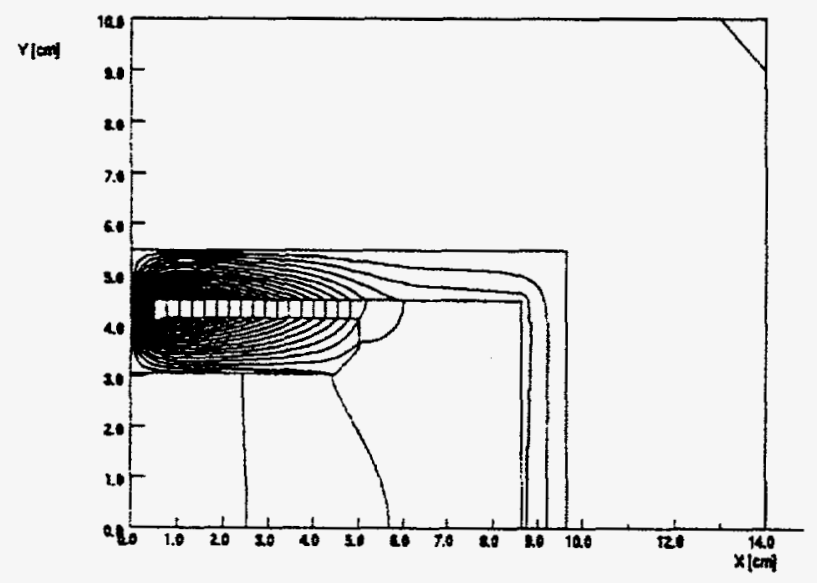

Figure 2: Magnetic flux of the deflector magnet.

\subsection{Electrostatic Deflector}

The mechanical design of the LEUTL electrostatic deflector is a compact functional design that will support a $30-\mathrm{kV}$ potential between precisely aligned electrodes while being ultra-high-vacuum compatible. To minimize welding in the construction of the component that is enclosed within the permanent magnet field. the unit body is machined from one piece of $316 \mathrm{~L}$ stainless steel. The tubing welded to the body is also $316 \mathrm{~L}$ stainless steel in order to reduce magnetism of essential weld joints. The ectrodes are also of one piece $316 \mathrm{~L}$ stainless steel construction. The electrical design of the kicker requires that the electrodes are supported by insulated standoffs and alinnad to within $0.1 \mathrm{~mm}$. This is achieved by mounting the electrodes on pairs of $35 \mathrm{kV}$ vacuum-rated ceramic standoffs. The standoffs are stock alumina ceramic cylinders that are tapped at both ends to facilitate attachment.

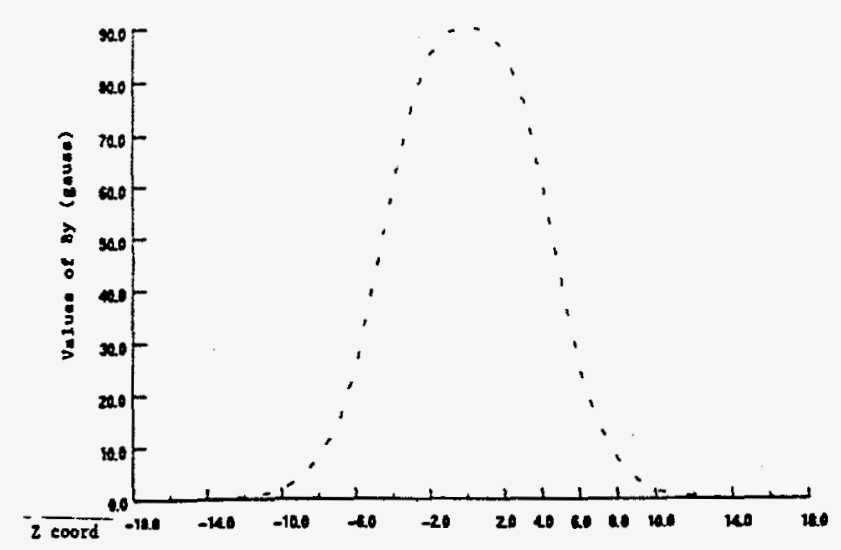

Figure 3: Magnetic field intensity in longitudinal direction.

The tapped holes are also employed to allow the horizontal positioning of the electrodes. The standoffs are tightly attached to threaded studs on the electrodes and then freely attached to studded flanges on ports on the body. The ports are sealed with rotatable Conflat flange joints. Rotating the joints before final sealing allows the positioning of the electrodes. The adjustable joints are preloaded with compression springs to maintain the position of the electrodes. The port positions are accurately machined to locate the electrodes longitudinally and vertically. Electrode alignment is measured on an electronic coordinate measuring machine. After electrode alignment, $35 \mathrm{kV}$ vacuum-rated power feedthroughs are mechanically attached to the electrodes with silver-plated set screws. The kicker design maintains a modular assembly in which the feedthroughs, electrodes, and standoffs can be easily replaced.

Figure 4 shows the electric kicker chamber design. A water-cooled beam dump is integrated to the vacuum flange in the left-hand side. The electrodes are slightly shifted in order to eliminate beam scraping with magnet only deflection. For reliable high voltage operation, all body and electrode surfaces exposed to high voltage are rounded and electropolished to remove burrs and surface contaminants. An extra port with a $53.8-\mathrm{mm}$ flange is provided for possible higher-order mode damping.

\subsection{Pulsed Power Supply}

The power supply for the electrostatic chopper consists of a high voltage unit, a thyratron switch, and a delay line. A picture of the circuit is shown in Figure 5.

The high voltage unit is an EMI 500A, which is a 30$\mathrm{kV}$ constant-current-charging supply by Electronic Measurements, Inc. This supply outputs a constant current so the voltage on the delay line, like a capacitor for $D C$, rises linearly. When the voltage reaches the setpoint, the supply automatically switches to the voltage regulating mode to maintain a constant output voltage. The high voltage supply can be controlled by a charging command to minimize the time when the system carries high voltage, to reduce the stress on the insulation material. 


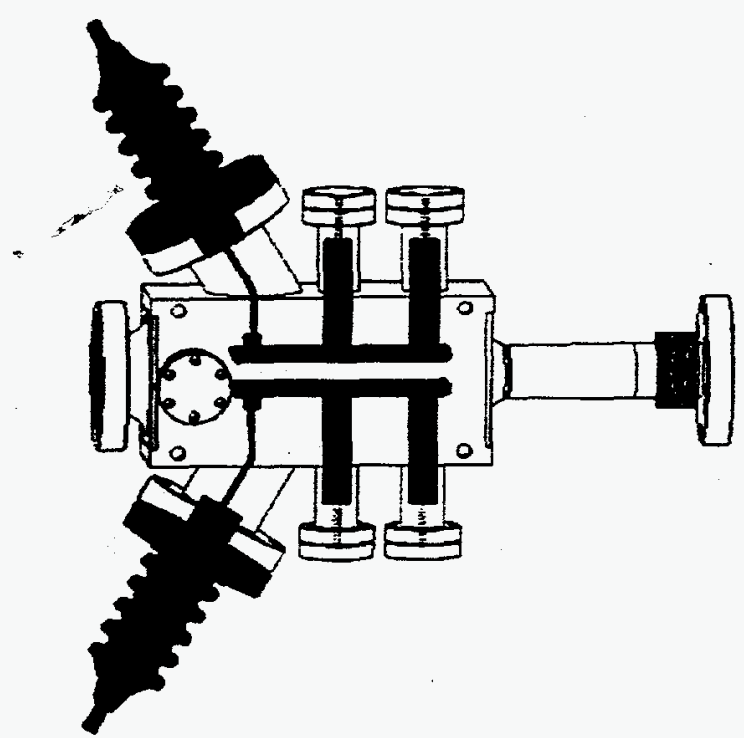

Figure 4: Electric kicker chamber design.

The thyratron is an EEV CX1 $154 C$. It is a single-gap tube rated at $35 \mathrm{kV}$. Its grid 1 is driven with a current pulse of $23 \mathrm{~A}$, and grid 2 is driven with a voltage pulse of $800 \mathrm{~V}$ plus a negative bias of $150 \mathrm{~V}$. To reduce the stray inductance which will slow down the speed of the pulse and cause difficulty for impedance matching, the thyratron housing is carefully designed as a coaxial structure. The terminating resistors for the coax cables are also integrated as part of the thyratron structure. The measured turn-on time (the voltage goes from $100 \%$ to 0 ) is less than $20 \mathrm{~ns}$.

The delay line is made of high voltage coaxial cable 2124 manufactured by Dielectric Sciences. Inc. The cable has a characteristic impedance of $61 \Omega$ The length of the short cable is about $1.8 \mathrm{~m}$ and is the minimum necessary to make the connection between the thyratron and one electrode. At the other electrode side, a capacitor-resistor string is connected to the short cable. The purpose of the string is to eliminate the overshoot caused by the imperfection in the impedance match at the thyratron. The side effect of the string is that the rise time of the pulse is slowed down to $50 \mathrm{~ns}$ instead of the 20 ns thyratron turnon time. The propagation speed of the delay line is $6.6 \mathrm{~ns} /$ $\mathrm{m}$. This means the required length of the delay line is $22.9 \mathrm{~m}$.

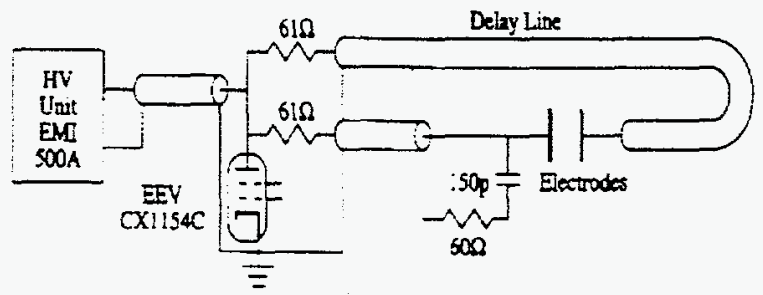

Figure 5: Pulsed power supply circuit schematic

\footnotetext{
diagram.
}

Figure 6 shows a measured voltage waveform across a mock-up deflector. At the time this paper was written, the delay line was $30.5 \mathrm{~m}$ long. Therefore, the pulse width is 200 ns.

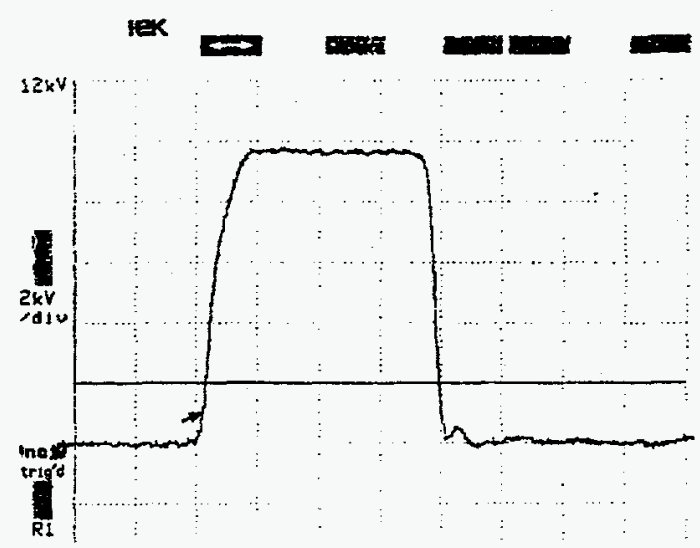

Figure 6: Outputs from high voltage pulsed power supply. $50 \mathrm{~ns} / \mathrm{div}$.

\section{DISCUSSION}

The complete beam chopper system has been fabricated for the design described earlier in this paper. The electrostatic kicker structure is driven by a switched high voltage pulsed power supply through a delay line. The power supply has been made and tested for $10-\mathrm{kV}$ operation with a good pulse waveform. With proper adjustment of the capacitance parallel to the load, the pulse risetime slightly degraded but the overshoot has been reduced. The kicker system will be assembled and tested completely before installation in the beamline.

\section{ACKNOWLEDGMENT}

We would like to thank Kerry Potter for his contribution to this project in the mechanical design process for design, detailing, and integration of the chopper into the beamline. This work was supported by the U.S. Department of Energy, Office of Basic Energy Sciences, under Contract No. W-31-109-ENG-38.

\section{REFERENCES}

[1] S. V. Milton et al., "The Advanced Photon Source Low-Energy Undulator Test Line," these proceedings.

[2] Specified by the Magnetic Material Producers Association Standard Specification for Permanent Magnet Materials-0100 (-90).

[3] Code OPERA-2d (formerly PE2D) is available from Vector Fields. Inc., Aurora. Illinois 